\title{
Recorregut de recerca geològica i mineralògica per la comarca del Baix Ebre: des de Roquetes als Reguers al Caragol i al Mont Caro
}

Josep Maria Mata-Perelló

Joaquim Sanz Balagué

\section{XARAGALL \\ REVISTA DE CIÈNCIES DE LA CATALUNYA CENTRAL} n. 3

MARÇ 2015 


\title{
RECORREGUT DE RECERCA GEOLÒGICA I MINERALÒGICA PER LA COMARCA DEL BAIX EBRE: DES DE ROQUETES ALS REGUERS AL CARAGOL I AL MONT CARO
}

\author{
Josep Maria Mata-Perelló \\ Museu de geologia Valentí Masachs, Escola Politècnica Superior d'Enginyeria de Manresa \\ (EPSEM), Universitat Politècnica de Catalunya · BarcelonaTech (UPC), 08272 Manresa, Spain
}

\section{Joaquim Sanz Balagué}

Departament d'Enginyeria Minera i Recursos Naturals (EMRN), Escola Politècnica Superior d'Enginyeria de Manresa (EPSEM), Universitat Politècnica de Catalunya . BarcelonaTech (UPC), 08272 Manresa, Spain

Paraules clau: Sistema Mediterrani, Patrimoni miner

\section{Resum}

Itinerari realitzat el 12 d'abril de 2014. En aquesta ocasió, el recorregut de l'itinerari discorrerà, en la seva totalitat pel Sistema Mediterrani, tot i que dintre de la denominada Zona d'Enllaç, pels seus indrets meridionals; i més exactament per la Serralada Prelitoral Catalana, pel Mont Caro.

Així, l'itinerari discorrerà en la seva major part entorn a la denominada Falla del Baix Ebre, tant pel bloc esfondrat (per la Depressió del Baix Ebre), com per l'aixecat (pels Ports de Tortosa). Així, el recorregut s'iniciarà a la primera sotsunitat esmentada, per la qual es transitarà breument, fins iniciar l'ascens cap al Mont-Caro.

Per altra banda, el recorregut transitarà íntegrament per la Regió de Tortosa, i més concretament per la comarca del Baix Ebre, una de les quatre que constitueixen aquesta demarcació, també coneguda sovint amb el nom genèric de les Terres de l'Ebre. 


\section{Objectius fonamentals}

A través d'aquest itinerari, i d'acord amb el sentit de la marxa del mateix, s'intentaran aconseguir els següents objectius:

1. Estudi i observació dels materials mesozoics (representat per tots els seus trams, pel Triàsic, del Juràssic i del Cretàcic, i en especial pels dos darrers, segons els indrets) els quals formen part de la Serralada Prelitoral Catalana, i més concretament dels relleus dels Ports de Tortosa. Tot i així, en aquest recorregut sols trobarem afloraments dels materials carbonatats juràssics, del Dogger i del Liàsic. Aquests materials els trobarem a diferents indrets del recorregut de l'itinerari entre Reguers i el Mont Caro.

2. Observació dels materials quaternaris (i si s'escau també dels cenozoics) que reblen la Depressió del Baix Ebre. Així, transitarem per aquests sectors al principi de l'itinerari, entre Tortosa i les immediacions de la població dels Reguers, i també entre aquesta darrera i la carretera d'ascens al Mont-Caro.

3. Observació de l'estructura de les unitats geològiques anteriorment esmentades. En especial de la Depressió del Baix Ebre i de la Serralada Prelitoral Catalana (pels indrets corresponents als Ports de Tortosa). I tanmateix, observació a gran escala de la Falla del Baix Ebre, a través del denominat Graó de Tortosa - Onda

4. Estudi, si s'escau, d'algunes mineralitzacions situades entre els materials mesozoics de la Serralada Prelitoral Catalana. Entre aquestes, farem esment de les mineralitzacions ferruginoses associada a "hard-grounds", localitzada prop del Mont Caro, la qual es troba ubicada entre els materials carbonatats del Juràssic Mig.

5. Observació de diferents explotacions que anirem trobant al llarg del recorregut de I'itinerari. Entre aquestes farem esment de explotacions de materials carbonatats detrítics situades al Mont Caro, dintre dels Ports de Tortosa. Els materials extrets som emprats com $a$ àrids.

6. Observació de l'impacte produït sobre el Medi Natural, a partir de les explotacions anteriors.

7. Observació, si s'escau, de les tasques de restauració mediambiental realitzades a les explotacions anteriors, per tal de reduir l'impacte produït sobre el Medi natural.

8. Observació i valorització de diferents aspectes relacionats amb el Patrimoni Geològic $i$ Miner. 


\section{Antecedents}

No tenim coneixement de cap antecedent bibliogràfic, en relació amb el recorregut d'aquest itinerari, ni de caire total (relatiu a tot l'itinerari), ni de caire parcial. Solament farem esment de dos treballs nostres (Mata Perelló 2001, 2005 i 2011), els quals discorren per uns recorreguts parcialment coincidents amb el present.

Pel que fa a l'estructura geològica dels indrets pels quals discorrerà el recorregut de l'itinerari, farem esment de dos treballs generals, relatius al conjunt dels Països Catalans: Guimerà et altri (1992), i Riba et altri (1976). En aquest aspecte, també farem esment de les publicacions de I'IGME (1973 i 1979), relatius a les contrades per les quals discorrerà el recorregut d'aquest itinerari.

Pel que fa a l'estudi de les mineralitzacions situades al llarg del recorregut, farem un especial esment d'un altre treball nostre, relatiu al conjunt de les mineralitzacions situades arreu de Catalunya. Es tracta del treball de Mata Perelló (1991).

Tots aquests treballs esmentats, figuraran per ordre alfabètic a l'apartat dedicat a les REFERĖNCIES BIBLIOGRÀFIQUES, al qual ens remetem.

\section{Recorregut de l'itinerari}

El recorregut d'aquest itinerari començarà a la localitat de Roquetes, des d'on s'anirà tot seguit cap a la població dels Reguers, una localitat agregada de Tortosa. A partir d'aquí cal anar cap a la carretera que ascendeix cap al Mont-Caro. Així, ens aproparem a la cruilla de la carretera amb el inacabat Canal de Xerta.

A partir d'aquest indret iniciarem en realitat el recorregut de l'itinerari, a uns $4 \mathrm{Km}$ i escaig de Roquetes. Així ens caldrà ascendir cap al cim del Mont-Caro, realitzant diferents aturades al llarg de la carretera que hi condueix. En arribar-hi, en aquest indret finalitzarà el recorregut de I’itinerari.

\section{Advertiments previs}

Com en altres recorreguts de RECERCA GEOLÒGICA I MINERALÒGICA... si es disposa del temps suficient, poden efectuar-se passant per totes les parades i filloles. En cas contrari, recomanem reestructurar el recorregut, prescindint de les anomenades PARADES CONDICIONALS, i d'altres si s'escau.

També recomanem de cercar la informació més adient, sobre els trams a recórrer mitjançant camins de terra, o de pista.

Per altra banda, recomanem tenir una cura extrema de la NATURA, evitant qualsevol forma d'agressió sobre ella, o de fer-n'hi un mal ús del que en ofereix la nostra mare Terra. 


\section{Descripció de l'itinerari}

\subsection{Parada 1 - CONDICIONAL. IMMEDIACIONS DEL BARRANC DE FARRUBIO, CARRETERA AL MONT-CARO, (terme municipal de Roquetes, comarca del Baix Ebre). (Full 521).}

El recorregut de l'itinerari, caldrà iniciar-lo a la localitat de Roquetes. Aquí ens caldrà seguir per la carretera que ascendeix cap al Mont-Caro, passant per prop dels Reguers. A uns $4^{\prime} 4 \mathrm{Km}$ després de creuar el Canal de Xerta, després d'agafar la carretera, ens caldrà fer la present aturada. Així, des de Roquetes, haurem fet un recorregut molt proper als $8 \mathrm{Km}$, per tal d'arribar fins a l'indret on fem la present aturada, fins aquí.

En aquest recorregut hem anat trobant inicialment els materials quaternaris de la Depressió del Baix Ebre, els quals són de caràcter detrític i pertanyen fonamentalment a l'Holocè. Després, en començar a pujar cap al Mont-Caro hem travessat la Falla del Baix Ebre i hem començat a trobar afloraments carbonatats del Juràssic, fonamentalment del Dogger, al que pertanyen els afloraments propers que ara veiem. Aquests materials es veuen força plegats. (fotografia 1 )..

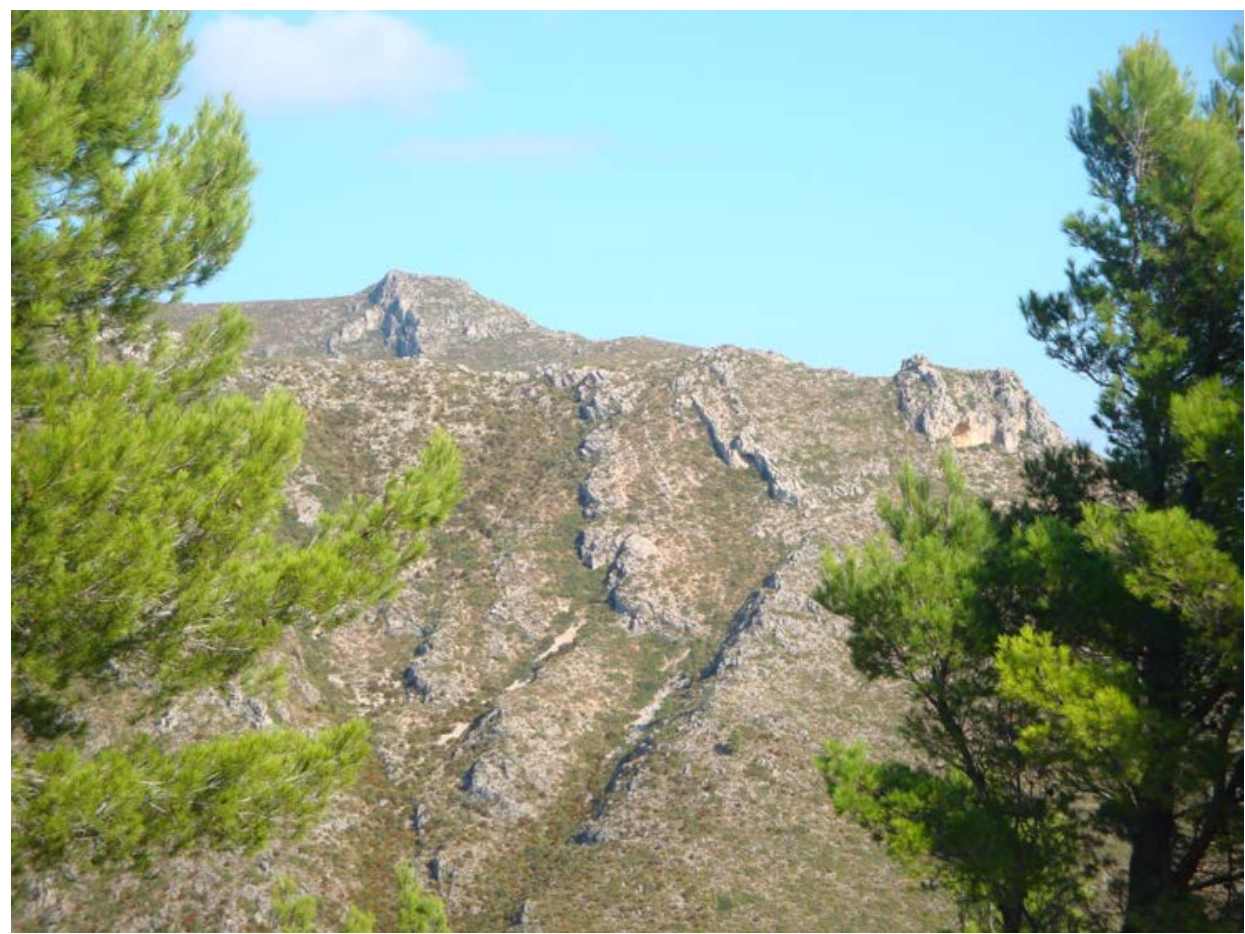

Fotografia 1. Un aspecte dels materials juràssics plegats.

En aquest indret, mirant cap a I'altra banda del Barranc de Farrubio es pot observar clarament un hard-ground ferruginós, fent-se clarament palesos els colors rogencs de I'HEMATITES. 


\subsection{Parada 2 - CONDICIONAL. CARRETERA AL MONT-CARO, A 5'2 Km DE LA CRUÏLLA AMB LA CARRETERA DEL CANAL DE XERTA, (terme municipal de Roquetes, comarca del Baix Ebre). (Full 521).}

Des de la parada anterior, cal continuar ascendint cap al Mont-Caro. En arribar a les immediacions del Km 5’2 des del Canal de Xerta, caldrà fer una nova aturada, a uns 0’8 Km de la parada anterior.

En aquest trajecte, hem continuat trobant els materials mesozoics anteriorment esmentats, els quals pertanyen al Juràssic, fonamentalment al Dogger, del Juràssic Mig. Per d'altra banda, cal fer esment de que aquests materials són eminentment carbonatats, de caràcter calcari generalment.

En aquest indret es fa palesa una falla entre els materials anteriors. L'esquema d'aquesta és el següent, (esquema 1).

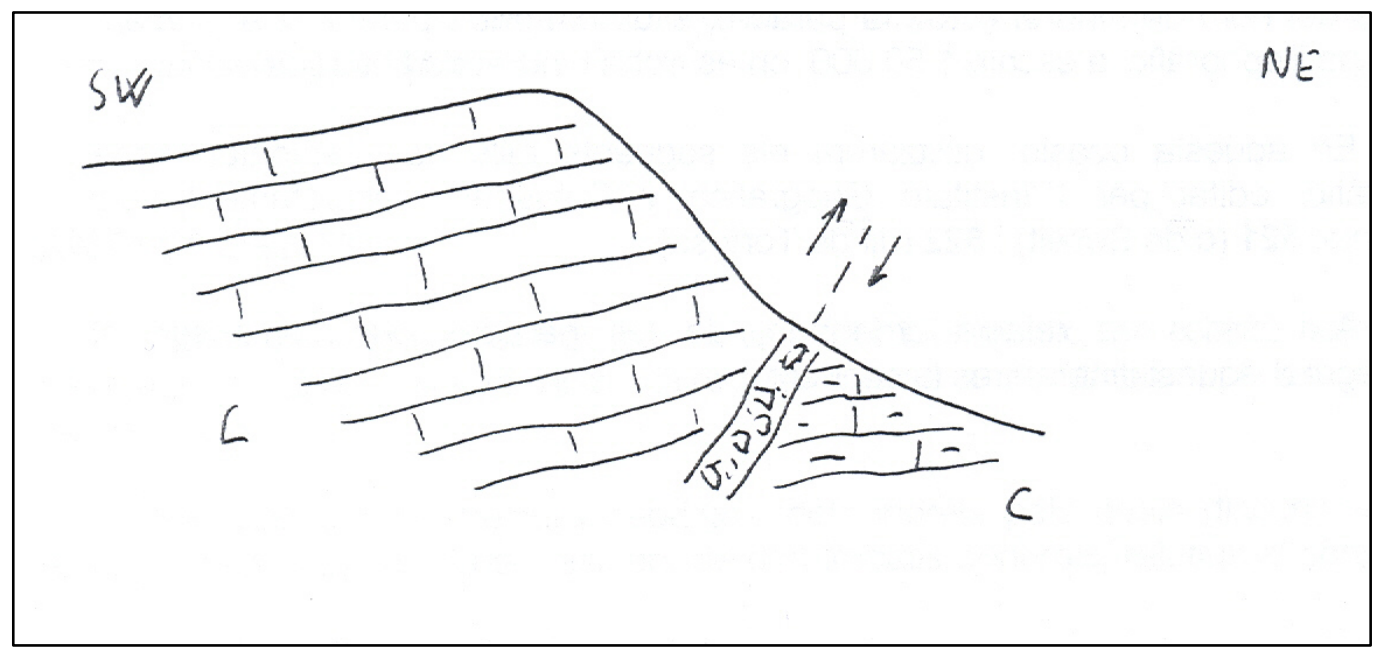

Esquema 1

\subsection{Parada 3. CARRETERA AL MONT-CARO, A 6’6 Km DE LA CRUÏLLA AMB LA CARRETERA DEL CANAL DE XERTA, (terme municipal de Roquetes, comarca del Baix Ebre). (Full 521).}

Després de fer la parada anterior, cal continuar cap al Mont-Caro per la carretera procedent de Roquetes. En arribar a les immediacions del Km 6’6 del Canal de Xerta, caldrà fer una nova aturada, a uns $1^{\prime} 4 \mathrm{Km}$ de l'anterior.

En aquest recorregut hem continuat trobant els materials mesozoics. Aquests són els que es troben a l'indret on ara ens trobem situats. Aquí, aquests es troben intensament fracturats i replegats. Un esquema d'aquest aflorament és el següent. (esquema 2). 


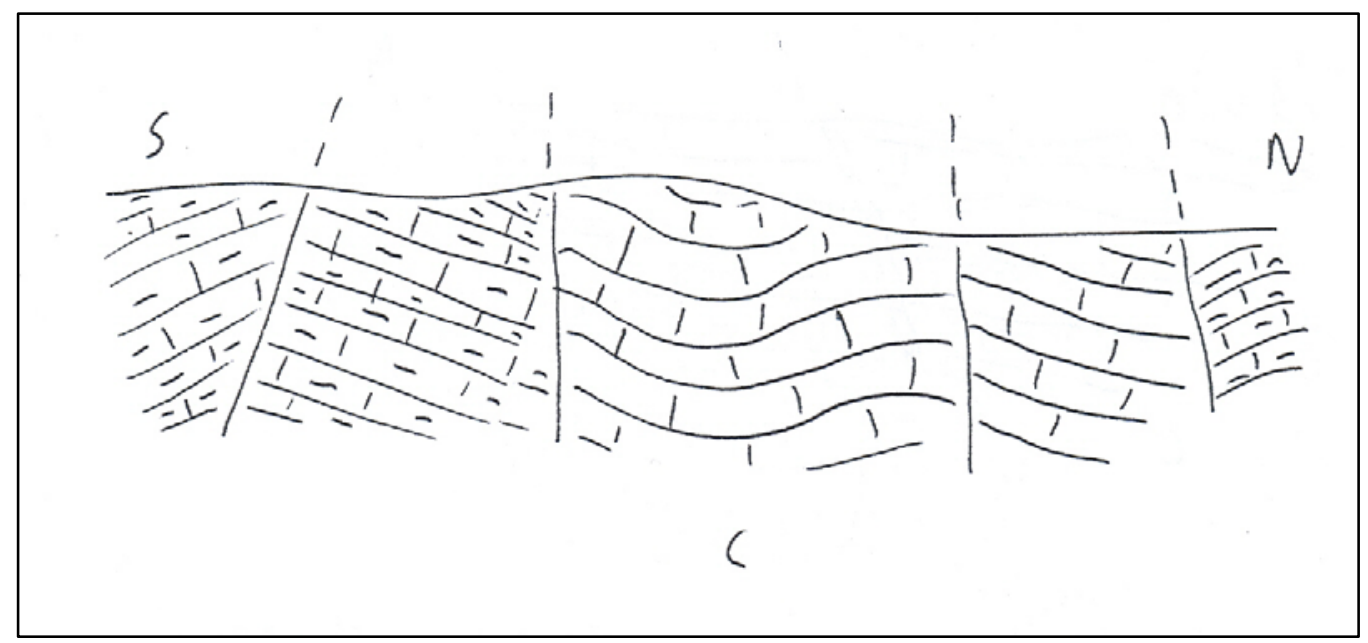

Esquema 2

\subsection{Parada 4 - CONDICIONAL. MIRADOR DE LA VALL D’ALFARA, CARRETERA AL MONT-CARO, A 8’8 - 9’1 Km DE LA CRUÏLLA AMB EL CANAL DE XERTA, (terme municipal de Tortosa, comarca del Baix Ebre). (Full 521).}

Després de fer la parada anterior cal continuar cap al Mont-Caro per la carretera que venim seguint des de la cruilla del Canal de Xerta. Entre 8'8 i 9'1 Km des de l'esmentada cruïlla caldrà fer una nova aturada, a uns 2'2 - 2'5 de l'anterior aturada.

En aquest recorregut hem continuat trobant afloraments mesozoics eminentment carbonatats, els quals pertanyen ara al Juràssic Inferior, al Liàsic. Aquests materials són generalment de caràcter carbonatat.

Des d'aquest indret, mirant cap al Nord, es pot veure una interessant perspectiva del Vall d'Alfara. Aquest es troba situat al Nord d'on ara ens trobem ubicats. (fotografia 2).

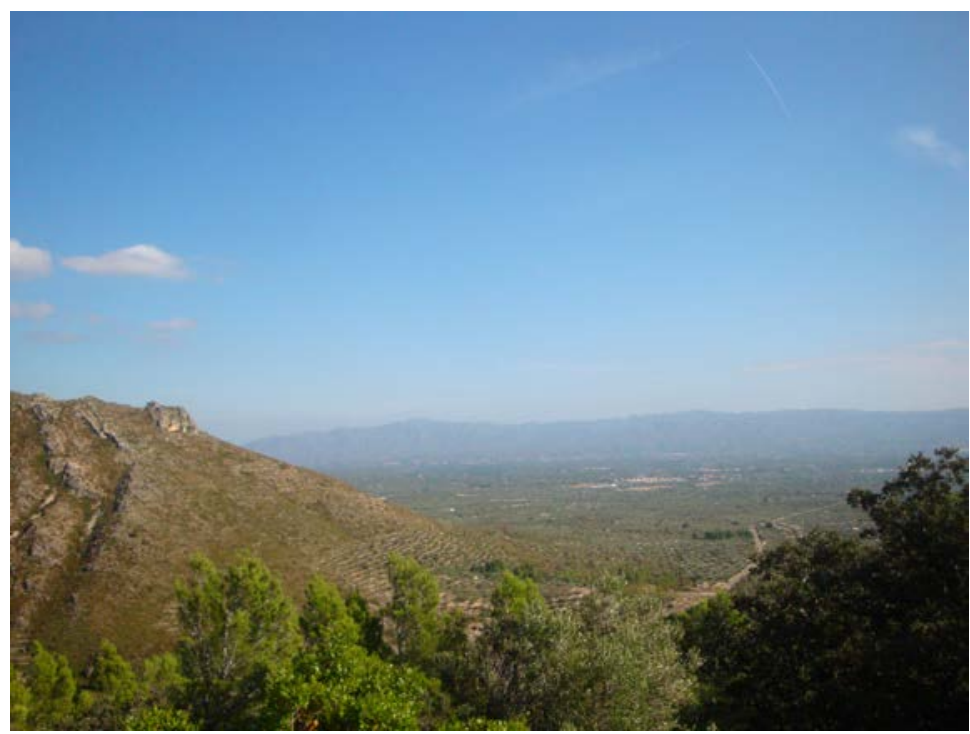

Fotografia 2. Observació del Baix Ebre, des de les immediacions del Caragol 


\subsection{Parada 5. IMMEDIACIONS DEL CARAGOL, CARRETERA AL MONT - CARO, A 9`4 Km DE LA CRUÏLLA AMB LA CARRETERA DEL CANAL DE XERTA, (terme municipal de Tortosa, comarca del Baix Ebre). (Full 521).}

Després de fer la parada anterior, cal continuar ascendint cap al Mont-Caro. En arribar a les immediacions del Km 9’4, des del Canal de Xerta caldrà fer una nova aturada, a uns 0’3 Km de l'anterior.

En aquest recorregut, hem continuat trobant els materials carbonatats mesozoics, que aquí pertanyen fonamentalment al Juràssic Mig, concretament al Dogger. Aquests materials es troben aquí fracturats, fent-se força palesa una falla.

Un esquema d’aquesta falla, és el següent. (esquema 3).

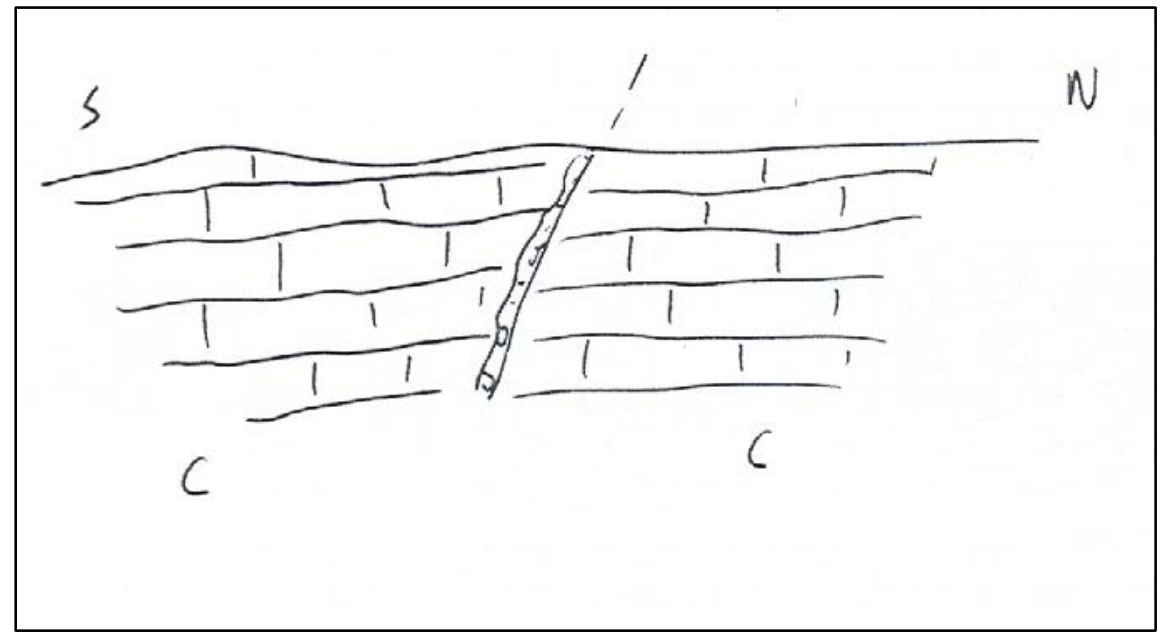

Esquema 3

\subsection{Parada 6. IMMEDIACIONS DE LA BARCINA, CARRETERA AL MONT-CARO, A 11'6 - 12'7 Km DE LA CRUÏLLA AMB LA CARRETERA DEL CANAL DE XERTA, (terme municipal de Tortosa, comarca del Baix Ebre). (Full 521).}

Des de la parada anterior, cal continuar per la carretera que es va seguint, ascendint cap al Mont-Caro. En arribar al tram comprés entre els Km 11'6 i 12'7, des del Canal de Xerta, caldrà fer una nova aturada; entre 2’6 i 3’7 Km des de la parada anterior.

En aquest recorregut, des de la parada anterior, hem continuat trobant els materials esmentats a les parades anteriors, els quals pertanyen majoritàriament al Juràssic. Per aquests indrets, els materials pertanyen al Dogger.

En aquest tram de la carretera hi ha diverses explotacions, ara aturades, en les quals s'estenen les calcàries cretàciques, que aquí es troben molt fracturades. Un cop extretes s' utilitzaven com a àrids artificials per a la construcció, fonamentalment. 


\subsection{Parada 7. IMMEDIACIONS DE LA PEIRA, CARRETERA AL MONT-CARO, A 14’1 Km DE LA CRUÏLLA AMB LA CARRETERA DEL CANAL DE XERTA, (terme municipal de Tortosa, comarca del Baix Ebre). (Full 521).}

Des de la parada anterior, cal continuar per la carretera que va pujant cap al Mont-Caro. Aviat es trobarà la cruïlla d'on surt la carretera que se'n va cap a Beseit i Fredes. Tot i així, caldrà pujar cap a l'esmentat Mont-Caro. A uns $1^{\prime} 4 \mathrm{Km}$ de la parada anterior, en caldrà fer-n'hi una altra.

En aquest recorregut, hem continuat trobant els materials esmentats a les parades anteriors (concretament, els nivells carbonatats del Dogger), que aquí es troben força fracturats. Per d'altra banda, en aquest recorregut, hem passat molt propers a l'encavalcament del Mascar, de direcció clarament "catalana"; és a dir NE - SW.

Així, a la vora de la carretera, just després d'unes fortes corbes es fan força paleses aquestes falles. Un esquema d'aquestes falles és el següent. (esquema 4).

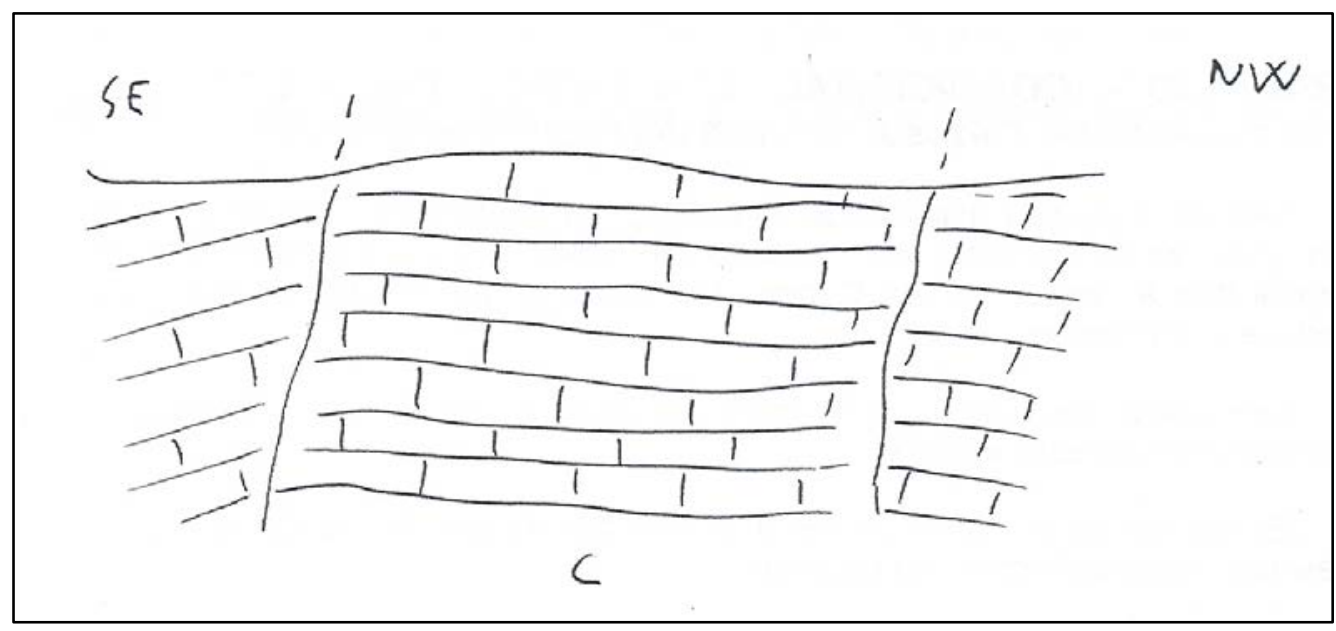

Esquema 4

\subsection{Parada 8. CARRETERA AL MONT-CARO, A 14'8 Km DE LA CRUÏLLA AMB LA CARRETERA DEL CANAL DE XERTA, PUJADA CAP AL MONT CARO, (terme municipal de Tortosa, comarca del Baix Ebre). (Full 521).}

Des de la parada anterior, cal continuar per la carretera que es dirigeix cap al Mont-Caro. En arribar a les immediacions del Km 14'8 (des del Canal de Xerta) caldrà fer una nova aturada, a uns $700 \mathrm{~m}$ de l'anterior.

En aquest recorregut s' han continuat fent palesos els materials carbonatats esmentats a les parades anteriors. Aquests materials es troben força replegats. Per d'altra banda també estan força carstificats. Aquests materials pertanyen al Juràssic i concretament ara al Dogger.

En aquest indret es fa palesa una cova, desenvolupada entre dues fractures que tallen als materials carbonatats mesozoics. 


\subsection{Parada 9. CIM DEL MONT-CARO, (terme municipal de Roquetes, comarca del Baix Ebre). (Full 521).}

Des de la parada anterior cal continuar per la carretera cap al Mont-Caro. En arribar-hi, a uns 0 '9 Km de la parada anterior, ens caldrà fer-n'hi un altra.

En aquest trajecte, hem continuat trobant els materials esmentats a les parades anteriors, els quals segueixen sent eminentment carbonatats $i$ pertanyen al Juràssic. Concretament pertanyen als trams superiors del Dogger i al Malm; és a dir: al Juràssic Superior.

Des d'aquest indret, força enlairat, es pot gaudir d'un bon lloc d'observació, tant de la Serralada Prelitoral Catalana (a traves de les seves sotsunitats) com de la llunyana Depressió Geològica de I'Ebre. Tanmateix es fa força palès el Delta de l'Ebre. (fotografia 3)..

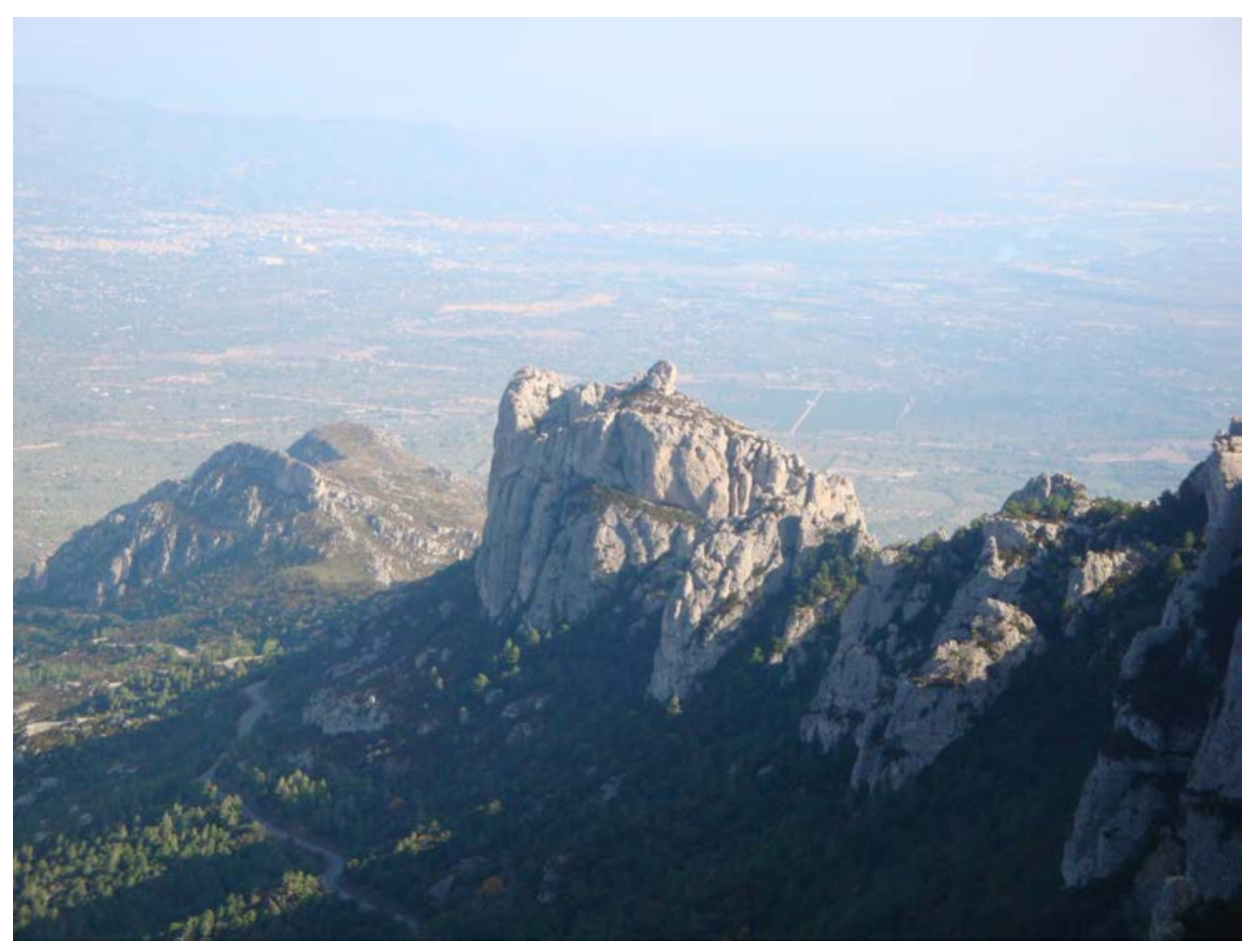

Fotografia 3. Un aspecte del Baix Ebre, des del Mont Caro

En aquest indret finalitza el recorregut de l'itinerari 


\section{Bibliografia}

GUIMERÀ, J. et altri /1992).- Geologia (II), Història Natural dels Països Catalans, Vol.2, 547 pag. Enciclopèdia Catalana, $\mathrm{S}, A$, , Barcelona.

IGME (1973).- Mapa Geológico de España, a escala 1:50.000, 2a Serie. Full i memória nº 546 (Ulldecona). Instituto Tecnológico y GeoMinero de España. Ministerio de Indústria. Madrid.

IGME (1979).- Mapa Geológico de España, a escala 1:50.000, 2a Serie. Full i memória nº 522 (Tortosa). Instituto Tecnológico y GeoMinero de España. Ministerio de Indústria. Madrid.

MATA-PERELLÓ, J.M. (1991).- Els Minerals de Catalunya. Institut d'Estudis Catalans. Arxius de la Secció de Ciències, T.XLVIII, 506 pag. Barcelona.

MATA-PERELLÓ, J.M. (2001).- Recorregut de recerca geològica i mineralògica per la comarca del Baix Ebre: des dels Reguers al Mont Caro / Inèdit, 10 pag. Manresa.

MATA-PERELLÓ, J.M. (2005).- Recorregut de recerca geològica i mineralògica per la comarca del Baix Ebre: des de Tortosa i Roquetes cap als Reguers i cap al Mont Caro. Inèdit. 10 pàgines. Manresa.

MATA-PERELLÓ, J.M. (2011).- Recorregut de recerca geològica i mineralògica per la comarca del Baix Ebre: des de Roquetes als Reguers i al Mont Caro. Inèdit. 8 pàgines. Manresa

RIBA, O. et altri (1976).- Geografia Física dels Països Catalans. Edit. Ketres, 254 pàgines. Barcelona. 